Article

\title{
Fashion Promotion on Instagram with Eye Tracking: Curvy Girl Influencers Versus Fashion Brands in Spain and Portugal
}

\author{
Luis Mañas-Viniegra ${ }^{1, *(\mathbb{D}}$, Ana-Isabel Veloso ${ }^{2}$ and Ubaldo Cuesta ${ }^{3}$ \\ 1 Department of Applied Communication Science, Complutense University of Madrid, 28040 Madrid, Spain \\ 2 Department of Communication and Art, University of Aveiro, 3810-193 Aveiro, Portugal \\ 3 Department of Theories and Analysis of Communication, Complutense University of Madrid, 28040 Madrid, \\ Spain \\ * Correspondence: lmanas@ucm.es
}

Received: 6 June 2019; Accepted: 19 July 2019; Published: 23 July 2019

check for updates

\begin{abstract}
The rise of Instagram, as the fastest growing social network in Spain and Portugal, and its incorporation into the communication strategies of beauty and fashion brands have posed some risks for younger followers in relation to the development of identity and self-esteem. A physical appearance acceptance movement has also begun, based on interaction with images, on which the social network is also based. The purpose of this research was to determine how attention is paid to fashion promotion and to the awareness of physical appearance acceptance by curvy influencers in comparison with communications by fashion brands on Instagram. The quantitative and qualitative methodology is based on the use of a biometric eye tracking technique applied to a sample of 120 participants from Spain and Portugal, matching the profile of the main users of Instagram: urban university women under 25 years old with an interest in fashion, and a self-perception as a curvy woman. The results point to more attention focused on the imperfections for which curvy influencers are raising awareness than on the fashion they promote when these awareness factors are more visible, as well as more attention focused on the fashion accessories worn by curvy brand models than those worn by the influencers, with specific and significant differences between Spanish and Portuguese audiences.
\end{abstract}

Keywords: Instagram; influencer; eye tracking; brand management; identity construction; curvy girls; body image; fashion

\section{Introduction}

Instagram has established itself as the fastest growing social network in Spain [1] and Portugal [2], with $45 \%$ and $50 \%$ penetration, respectively, and its frequency of use continues to increase, being the second social network to Facebook in the United States [3], Spain [4], and Portugal [2]. Globally, Instagram has 700 million users [5], of which $90 \%$ are younger than 35 years old and $75 \%$ live outside the United States [6], with Spanish users being fourth in the number of published stories. Instagram is one of 10 apps without which young people between 18 and 34 years of age from all over the world could not live [5]. Its audience is mostly female, urban, and between 16 and 25 years old, in the countries mentioned, with a preference for topics related to beauty, fashion, travel, and leisure.

The young profile of this social network's audience, based on interactions with the publication of images and videos, is subject to some risk in relation to the topics of interest. Some authors highlighted the usefulness of the visual elements provided by Instagram for cognitive analysis [7] of the relationship between food and health, whereas the image concept only corresponds to the hashtags used in $10 \%$ of cases. 
Therefore, confusion can result among younger followers, for whom Instagram can have a decisive influence on their lives, since they use their clothing as a means of communicating lifestyle, experiences, or feelings [8]. Photographs uploaded to Instagram can be used to predict some indications of depression [9] or a tendency toward thinness and body dissatisfaction among the female university audience if members of this group tend to compare themselves to other people [10]. People are motivated by three main factors to publish: self-approval, which is negatively related to self-esteem; belonging, related to being open to new experiences; and as a means of documentation, related to kindness and an extroverted character [11].

From a more positive point of view, Instagram has been associated with a movement for the acceptance of physical appearance in its relationship with beauty and fashion [12]. The rationale is that viewing self-acceptance images of other Instagram users, especially large-sized or curvy women [13], mitigates the negative impact that social networks have had on women's satisfaction with their bodies [14], mainly when they have low self-esteem [15]. This positive effect partially compensates for the social isolation caused by the intensive use of social networks [16], which is lower in the case of social networks based on images [17], and the influence that models and celebrities can have on eating disorders through Instagram [18]. The root of the problem is that exposure to images of models on Instagram contributes to women's body dissatisfaction [19].

In the context of responsible communication, increasing numbers of brands in the beauty and fashion sector have decided to replace extremely thin models in their advertising campaigns. Dove started the change in 2004 with its concept of "real beauty", and low-cost brands such as H\&M or Primark usually include models of various sizes, disabilities, or distinctive features in their communications.

It is among the youngest consumers that brands with a presence on social networks inspire more confidence, and $52 \%$ acknowledge having felt the influence of social networks in their purchases. Of the consumers, $75 \%$ recall having seen more brands' actions through influencers [4]. Despite the profile of young Instagram users, who prefer to relate digitally to brands, celebrities have more influence on their buying behavior, although the persuasive power is much stronger in the case of influencers on Instagram, given their credibility and predisposition to interaction [20].

Success, in terms of the number of followers and engagement by these promoters, is essential, since users of social networks more easily accept the photographs that have received more likes [21]. When interacting with fashion brands on their official Instagram accounts, perceived hedonism affects satisfaction, interaction, and real consumer behavior [22].

Influencers accumulate a large number of followers due to narratives based on their personal lives that create empathy and a connection with an audience with whom they have things in common. Those everyday experiences constitute the foundation of their publications, the purpose of which is to communicate information about the brands that they promote in a more subtle or explicit way [23]. Influencers with many followers are more influential when they, in turn, follow few accounts. The conversion of the earliest influencers into minor celebrities has meant that their original space has been occupied by second-generation micro-influencers with fewer followers, but with more specific common interests, and above all, with greater closeness and spontaneity. The consequence is that more engagement is provided when these requirements are met [24].

Although some authors continue to consider real friends to be those who are exclusively offline, regardless of whether that social circle was generated online or not [25], others differentiate between following people they know and people they do not know [26]. The curvy girl audience often finds greater understanding from these micro-influencers than their physical friends, since they transmit their social identity related to positivity and self-esteem, providing support to their community [27]. The social interaction and interpersonal persuasion exerted by influencers facilitate this task of promotion [28] to their followers. Therefore, this activity has aroused ethical concerns regarding the identification of a mere spontaneous promotion versus a promotional activity financed by a brand, for which a specific regulation of this activity has already been suggested [29], as has happened in other conventional media with regard to product placement. 
The reviewed authors agree that collaboration with influencers is useful for brands when implementing their communication strategies on social networks [30], although there are divergent opinions regarding the positive or negative consequences for a young female audience due to their use of Instagram in relation to their self-perception and body satisfaction. Differences may exist in perception between Spanish and Portuguese audiences, as these are two markets that most fashion brands share within their communication strategies. Ribeiro-Cardoso et al. [31] concluded from a self-administered survey that university students in Porto (Portugal) showed a positive attitude toward fashion advertising, although less positive than the attitude shown by the influencers.

\section{Materials and Methods}

The purpose of this research was to determine how the attention to fashion promotion by curvy girl influencers is processed compared to communications by fashion brands through their Instagram accounts. To do this, eye tracking was used as a neuromarketing technique to determine how the influencer or fashion brand emitting the message affects the attention paid by the audience to the fashion clothing being exhibited, the physical appearance of the curvy girl, and to the awareness activity.

Fashion brands are increasingly relying on the promotion of influencers in social networks. However, does the image of the influencer, while consistent with the corporate culture of the brand, cannibalize the product and the brand? Is the visual attention that is focused on the clothes promoted by the brand greater when is it shown by influencers than when the brand does so through its official channels with models? Do curvy girls encourage attention to be focused on the clothes rather than on their physical appearance, the influencer's own personality, or the environment of the images? Are there differences in the perception of the Spanish audience in comparison to that of the Portuguese?

\subsection{Objectives}

The main objective, for the purpose of offering answers to the abovementioned research questions, was to analyze the visibility of fashion brands on Instagram using, as a basis, the attention paid to such brands when presenting their products with the promotion of influencers compared to the use of models on their own accounts on the social network. The specific objectives were the following:

- To determine the effects of curvy girl influencers on the attention paid to fashion products compared to that achieved directly by brands with their own communications;

- To establish differences in the attention paid to curvy Spanish women and that paid to Portuguese women;

- To analyze the degree of attention paid to physical appearance related to fashion within the existing acceptance movement on Instagram.

\subsection{Research Instrument}

Neuromarketing is a discipline specifically used to measure the cognitive processing and effectiveness of advertising and marketing campaigns that focus on brands' target markets, based on a combination of neuroscience, psychology, and economics [32]. The main reason for its use is the limitations of individuals when consciously contributing information about their behavior through surveys, focus groups, or in-depth interviews [33]. The biometric eye tracking technique provides information about an individual's visual attention [34], based on eye movements toward areas of interest that take precedence over those that are transitory, or others that are ignored. To achieve this, the eye trackers model TOBII X3-120 and model X2-60 were used in Portugal and Spain, respectively. The attention triggers cognitive and affective processes, indicating the preferences of the audience, with a positive correlation between the attention observed by the eye tracking technique and memory [35-39]. These characteristics have led to a new term for this field of study, more adapted to the particularities of brand communication: neurocommunication [40]. 


\subsection{Sample and Data Collection}

In the study, 120 subjects voluntarily participated between the months of May and July 2018-these are the months when body image concerns play a central role-with their profiles matching the main users of Instagram: women between 18 and 25 years old, university students, and living in urban areas. The inclusion criteria included an interest in fashion, considering oneself a curvy woman, and having used Instagram in the previous week. Two study groups were organized: one was Portuguese $(50 \%)$ from the University of Aveiro (Group 1, G1), specially chosen because it offers numerous postgraduate courses in which students from the most populous cities in Portugal, Porto and Lisbon, converge, and the second was Spanish (50\%), involving students who were studying at Complutense University of Madrid (Group 2, G2).

A review of the scientific literature related to eye tracking studies placed the number required for a valid study sample between 15 and 50 participants [41-43]. Hence, the 60 participants in this research constitute an adequate sample.

The stimuli used were two publications on Instagram in 2018: from a curvy micro-influencer (@elenadevesa) with 80,300 followers (data as of 22 June 2018), far fewer followers than the big fashion influencers in Spain, like @dulceida (with 2.6 million followers), and from a low-cost fashion brand. Primark was chosen (5.8 million followers, as of 22 June 2018) because it shares the same target audience and has integrated curvy models into its communications, along with other profiles traditionally unrelated to fashion brands. The stimuli were presented randomly among others that were innocuous, with a maximum duration of $5 \mathrm{~s}$, creating two groups that allowed for a comparative analysis of @elenadevesa and @primark. The first group consisted of stimuli in which the model or influencer did not expressly show the beautiful imperfections that are part of the acceptance awareness they promote, despite these being peripherally present. The second group included stimuli in which the model or influencer appeared in a bikini, with the physical details that serve as the basis for this awareness being fully visible. With this perspective, areas of interest (AOIs) were delimited in the four stimuli analyzed (Figure 1) to compare images in bikinis with images using street clothes, attention to the face, different pieces of clothing, and the imperfections for which these curvy models try to raise awareness.

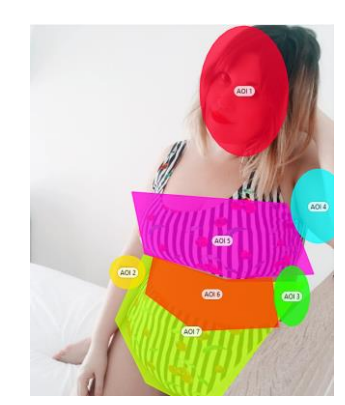

Stimulus $1(\mathrm{E} 1)$

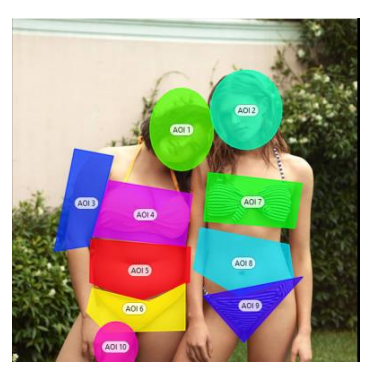

Stimulus 3 (E3)

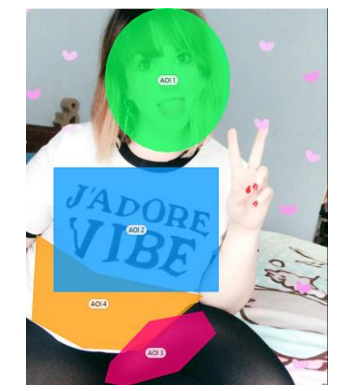

Stimulus 2 (E2)

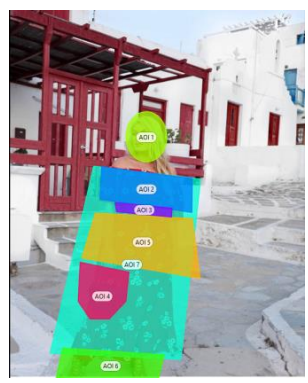

Stimulus 4 (E4)

Figure 1. Areas of interest (AOIs) of the four stimuli. Source: created using the Instagram accounts of @elenadevesa and @primark. 


\subsection{Data Analysis}

The dependent variable was the level of attention paid to the stimuli presented. The independent variables were the origins of the participants (Spain or Portugal), all of whom were in the same age range and had an interest in fashion, and the type of stimuli issuer (influencer or fashion brand). Visual attention is an essential element in the recognition and preference for a brand promoted through advertising, and young people can most easily focus their attention on the relevant information that is transmitted [44]. For this reason, we quantitatively evaluated the fixations count (FC); the duration (in number of seconds) for each fixation, or fixation duration (FD); the elapsed time from the appearance of the stimulus until the first fixation, known as time from fixation (TFF); and the total number of seconds of attention paid to the area of interest, or total fixation duration (TFD). Qualitatively, we evaluated the heat maps. The data obtained were processed statistically using SPSS v.25. All the research followed the protocols of the Research Ethics Committee of the Department of Theories and Communication Analysis at the Faculty of Media and Communication Studies at Complutense University of Madrid.

\section{Results}

Qualitatively, heat maps (Figure 2) revealed that the attention paid to the imperfections of which the influencer raises awareness was greater than to the fashion that they prescribe when the subject appears in a bikini, whereas attention was more focused on fashion and less on imperfections when the subject appeared in street clothing. For Primark, both in street clothes as well as in bikinis, the attention was more distributed amongst all of the elements of the image, whereas more attention was focused on the imperfections when dressed in swimsuits, which also occurred in the case of the influencer. We also observed that the non-curvy model attracted the least amount of attention.

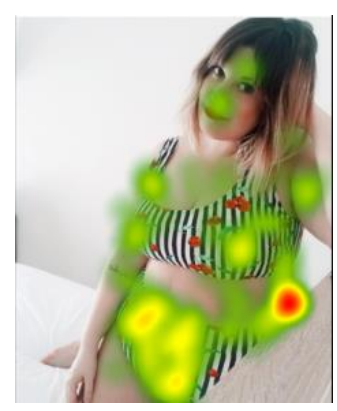

E1

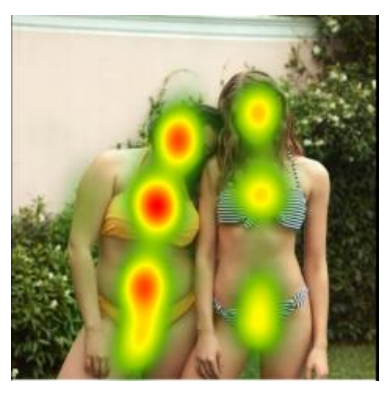

E3

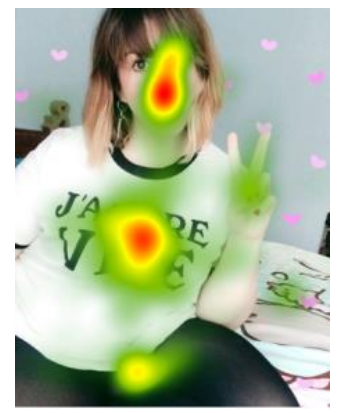

E2

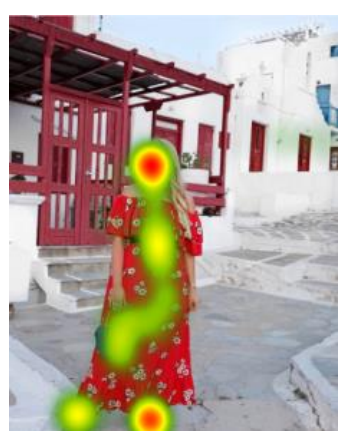

E4

Figure 2. Heat maps of the stimuli. Source: Created from the Instagram accounts of @elenadevesa and @primark. 
From a quantitative point of view, at least half of the AOIs registered an attention rate higher than $90 \%$ for all of the participants (Table 1), and all the stimuli, including the face, the bust, and the abdomen. The skin folds, or 'flank ridges', in the words of the influencer, had an attention rate greater than $50 \%$ in the stimuli with bikinis for the influencer, who emphasized this area in the text description, registering an attention rate of $78.30 \%$ of the participants, and a rate of $100 \%$ for street clothes, as shown in E2. The different aspects of fashion exhibited by the Primark model received an attention rate of more than $95 \%$ of the participants for the dress and bag category, whereas shoes remained at $72.50 \%$.

Table 1. Percentage of attention of the total number of participants to each AOI.

\begin{tabular}{|c|c|c|c|c|c|c|c|}
\hline \multicolumn{2}{|r|}{ E1 } & \multicolumn{2}{|r|}{ E2 } & \multicolumn{2}{|r|}{ E3 } & \multicolumn{2}{|r|}{$\mathrm{E} 4$} \\
\hline AOI 1 & 95.80 & AOI 1 & 100.00 & AOI 1 & 97.50 & AOI 1 & 95.00 \\
\hline AOI 3 & 78.30 & AOI 3 & 67.50 & AOI 3 & 26.70 & AOI 3 & 55.80 \\
\hline AOI 4 & 27.50 & AOI 4 & 61.70 & AOI 4 & 93.30 & $\mathrm{AOI} 4$ & 96.70 \\
\hline AOI 5 & 99.20 & & & AOI 5 & 93.30 & AOI 5 & 91.70 \\
\hline \multirow{3}{*}{ AOI 7} & & & & AOI 8 & 52.50 & & \\
\hline & & & & AOI 9 & 86.70 & & \\
\hline & & & & AOI 10 & 50.00 & & \\
\hline
\end{tabular}

Note: Area of interest (AOI).

A comparison of the AOIs with similar content in the four stimuli presented to all the participants shows that the attention paid to the face of the model or influencer was significantly different depending on the stimulus presented (Table 2). Less time was required to fix the first attention on the face of the curvy brand models than on that of the influencer $(p=0.036)$, even though the attention time for the AOI $(p=0.000)$ and the number of fixations was lower $(p=0.000)$, without the median duration of each fixation showing significant differences $(p=0.729)$. For the thin model, the delay in the first fixation was greater (TFF $=1.72)$, the viewing time of the AOI was shorter $($ TFD $=0.59 ; p=0.000)$, and the number of fixations was lowest ( $\mathrm{FC}=1.57 ; p=0.000)$, despite obtaining a non-significant second-highest average duration in each setting ( $\mathrm{FD}=0.37 ; p=0.729)$. There was no evidence, however, that the appearance of the influencer or the model wearing either a bikini or street clothes affected the attention on her face when comparing influencer and brand.

Table 2. Kruskal-Wallis test between similar AOIs.

\begin{tabular}{ccccccc}
\hline Fixation & E1-AOI 1 & E2-AOI 1 & E3-AOI 1 & E3-AOI 2 & E4AOI 1 & $p$-Value \\
\hline Average TFF & 1.06 & 1.24 & 0.82 & 1.72 & 0.61 & $0.036^{*}$ \\
Average TFD & 0.94 & 1.19 & 0.65 & 0.59 & 0.84 & 0.000 \\
Average FC & 3.06 & 3.99 & 2.17 & 1.57 & 2.07 & $0.000^{*}$ \\
Average FD & 0.31 & 0.30 & 0.30 & 0.37 & 0.41 & 0.729 \\
\hline
\end{tabular}

Note: TFF: Elapsed time from the appearance of the stimulus until the first fixation; TFD: Total number of seconds of attention paid to the area of interest; FC: Number of fixations count; FD: Duration in number of seconds of each fixation. ${ }^{*}$ denotes significant differences.

When comparing the skin fold voluntarily shown by the influencer as part of her awareness endeavor, which was stressed in the text accompanying the image, with that of the model of the bikini brand (Table 3), the first fixations occurred earlier in the images where it was most visible (TFF $=2.32$; $p=0.000$ ), with a greater total duration (TFD $=0.85 ; p=0.000$ ) and a higher number of fixations $(\mathrm{FC}=2.32 ; p=0.000)$, although the duration of each attention span was similar ( $\mathrm{FD}=0.37 ; p=0.097)$. In this respect, the influencer in a bikini and the brand model in a bikini produced similar records, without significant differences. 
Table 3. Kruskal-Wallis test between similar AOIs.

\begin{tabular}{ccccc}
\hline Fixation & E1-AOI 3 & E2-AOI 3 & E3-AOI 10 & $p$-Value \\
\hline Average TFF & 3.20 & 2.32 & 3.26 & $0.000^{*}$ \\
Average TFD & 0.49 & 0.85 & 0.42 & $0.000^{*}$ \\
Average FC & 1.48 & 2.32 & 1.35 & $0.000^{*}$ \\
Average FD & 0.35 & 0.37 & 0.33 & 0.097 \\
\hline
\end{tabular}

Note: * denotes significant differences.

However, when we analyzed the attention paid to the arm skin fold of the influencer in a bikini and of the curvy model in a bikini from the brand (Table 4), for whom it was much more discreet than in the previous image, the first received a first fixation significantly faster (TFF $=2.52 ; p=0.000$ ), although there were no differences in the TFD, FC, and FD records.

Table 4. Kruskal-Wallis test between similar AOIs.

\begin{tabular}{cccc}
\hline Fixation & E1-AOI 4 & E3-AOI 3 & $p$-Value \\
\hline Average TFF & 2.52 & 3.64 & $0.000^{*}$ \\
Average TFD & 0.39 & 0.41 & 0.386 \\
Average FC & 1.39 & 1.44 & 0.743 \\
Average FD & 0.28 & 0.29 & 0.528 \\
\hline
\end{tabular}

Note: ${ }^{*}$ denotes significant differences.

With regard to the attention paid to the bust in a bikini compared to clothes with a print on the bust (Table 5), the thin model once again had the lower records (TFF $=2.11, p=0.000$; TFD $=0.37$, $p=0.000 ; \mathrm{FC}=1.55, p=0.000$ ), despite an average fixation in line with the other stimuli (FD $=0.25$, $p=0.638$ ). However, whereas the influencer received faster attention, greater intensity, and greater duration for the shirt with the print on the bust (TFF $=0.45 ; \mathrm{TFD}=1.89 ; \mathrm{FC}=7.93 ; \mathrm{FD}=0.24$ ) compared to the bikini (TFF $=1.29 ; \mathrm{TFD}=0.84 ; \mathrm{FC}=0.56$; $\mathrm{FD}=0.24$ ), the bikini brand model received a higher number of fixations ( $F C=2.66$ versus 2.17 ), a greater total duration of these fixations (TFD $=0.64$ versus 0.53$)$, and the same average duration of each fixation $(\mathrm{FD}=0.25)$, whereas the first fixation occurred earlier for the printed dress than for the bikini $(\mathrm{TFF}=0.15$ versus TFF $=1.22$ ).

Table 5. Kruskal-Wallis test between similar AOIs.

\begin{tabular}{ccccccc}
\hline Fixation & E1-AOI 5 & E2-AOI 2 & E3-AOI 4 & E3-AOI 7 & E4-AOI 2 & $p$-Value \\
\hline Average TFF & 1.29 & 0.45 & 1.22 & 2.11 & 1.15 & $0.000^{*}$ \\
Average TFD & 0.84 & 1.89 & 0.64 & 0.37 & 0.53 & $0.000^{*}$ \\
Average FC & 3.56 & 7.93 & 2.66 & 1.55 & 2.17 & $0.000^{*}$ \\
Average FD & 0.24 & 0.24 & 0.25 & 0.25 & 0.25 & 0.638 \\
\hline
\end{tabular}

Note: * denotes significant differences.

Regarding the attention attracted by the abdomen (Table 6), the influencer in a bikini captured the first fixation $(\mathrm{TFF}=1.25 ; p=0.123)$, the greatest total time $(\mathrm{TFD}=1.79 ; p=0.000)$, the highest number of fixations, which was very high $(\mathrm{FC}=7.02 ; p=0.000)$, but with a lower duration of each fixation (FD $=0.25 ; p=0.009$ ) than that of the brand models. The influencer also received more attention on the abdomen in a bikini than when promoting street clothes $(\mathrm{TFF}=1.72$; $\mathrm{TFD}=0.40 ; \mathrm{FC}=1.68 ; \mathrm{FD}=0.25$ ). In the case of the Primark brand, the dressed model received the first attention the quickest $(\mathrm{TFF}=0.38)$, with the longest duration (TFD $=0.71$ ), and with the highest number of fixations $(\mathrm{FC}=2.60)$, although with a shorter attention span $(F D=0.26)$ compared to the brand models in a bikini. There were hardly any differences in attention between the curvy brand model in a bikini and the thin brand model. 
Table 6. Kruskal-Wallis test between similar AOIs.

\begin{tabular}{ccccccc}
\hline Fixation & E1-AOI 7 & E2-AOI 4 & E3-AOI 6 & E3-AOI 9 & E4-AOI 5 & $p$-Value \\
\hline Average TFF & 1.25 & 1.72 & 2.76 & 2.92 & 1.38 & 0.123 \\
Average TFD & 1.79 & 0.40 & 0.39 & 0.40 & 0.71 & $0.000^{*}$ \\
Average FC & 7.02 & 1.68 & 1.43 & 1.38 & 2.60 & $0.000^{*}$ \\
Average FD & 0.25 & 0.23 & 0.28 & 0.30 & 0.26 & 0.009 \\
\hline
\end{tabular}

Note: * denotes significant differences.

The comparison between the shirt that the influencer was promoting and the dress and accessories shown by the Primark model (Table 7) significantly demonstrate that the influencer captured less attention regarding the garment, in total time (TFD $=1.89 ; p=0.000)$, the high number of fixations $(\mathrm{FC}=7.93 ; p=0.000)$, and the average duration of each fixation ( $\mathrm{FD}=0.24 ; p=0.003)$, although with a shorter time until the first fixation appeared (TFF $=0.45 ; p=0.000$ ), in relation to that obtained by the dress promoted by the Primark model (TFF $=0.59 ; \mathrm{TFD}=2.61 ; \mathrm{FC}=8.98 ; \mathrm{FD}=0.29$ ). The attention paid to the clothes shown by the Primark model reveals that users move their gaze from top to bottom, in the order in which the garments appear after the dress (belt, bag, and shoes), and with proportionally increasing attention until they reach the shoes, with the latter having the best record of the three fashion elements $(\mathrm{TFF}=2.85 ; \mathrm{TFD}=1.02 ; \mathrm{FC}=2.25 ; \mathrm{FD}=0.29$ ).

Table 7. Kruskal-Wallis test between similar AOIs.

\begin{tabular}{ccccccc}
\hline Fixation & E2-AOI 2 & E4-AOI 3 & E4-AOI 4 & E4-AOI 6 & E4-AOI 7 & $p$-Value \\
\hline Average TFF & 0.45 & 1.74 & 1.98 & 2.85 & 0.59 & $0.000^{*}$ \\
Average TFD & 1.89 & 0.42 & 0.86 & 1.02 & 2.61 & $0.000^{*}$ \\
Average FC & 7.93 & 1.40 & 2.22 & 2.25 & 8.98 & $0.000^{*}$ \\
Average FD & 0.24 & 0.31 & 0.39 & 0.45 & 0.29 & $0.003 *$ \\
\hline \multicolumn{7}{c}{ Note: ${ }^{*}$ denotes significant differences. }
\end{tabular}

When we compared the same stimulus for both the thin and curvy models, both of whom were wearing bikinis, we first observed that the attention received by the slim model was lower. The U Mann-Whitney test involving pairs allowed us to detect significant differences between the models' faces-the curvy model's face was viewed sooner (TFF $=0.82 ; p=0.000)$, for a longer total period of time $(\mathrm{TFD}=0.65 ; p=0.059)$, and more frequently $(\mathrm{FC}=2.17 ; p=0.000)$, though for a shorter time for each fixation $(\mathrm{FD}=0.30 ; p=0.000)$, when compared to the thin model (TFF $=1.72$; TFD $=0.59$; $\mathrm{FC}=1.57 ; \mathrm{FD}=0.37$ ). With regard to the bust of the models, the curvy model also received greater attention, with the first fixation occurring faster (TFF $=1.22 ; p=0.000$ ) and lasting longer with regard to total length of time (TFD $=0.64 ; p=0.769)$, with a higher number of fixations ( $\mathrm{FC}=2.66 ; p=0.000$ ), and had the same average duration for each fixation $(\mathrm{FD}=0.25)$, when compared with the thin model $(\mathrm{TFF}=2.11 ; \mathrm{TFD}=0.37 ; \mathrm{FC}=1.55 ; \mathrm{FD}=0.25)$.

When comparing the attention paid to the belly of the curvy model compared to the thin model, we observed that the former received a significantly higher number of fixations $(\mathrm{FC}=2.62 ; p=0.000$ ) compared to the latter $(\mathrm{FC}=1.40)$, although with a nearly identical duration for each ocular fixation ( $F D=0.29$ and 0.30 , respectively). The thin model also received the attention first $(\mathrm{TFF}=2.71 ; p=0.000$ ) and faster than the curvy model $(\mathrm{TFF}=3.64)$. The attention registered on the lower abdomen was similar for the curvy and the thin models, with $p$-values between 0.263 and 0.763 . The curvy model received an average FC of 1.43 for this area of the body, well below the number of ocular fixations received on other parts of the body, whereas the thin model obtained a FC of 1.38, a figure similar to the number of fixations received by other parts of the body. The duration of each fixation in both cases was similar to that obtained in other areas.

Regarding differences between the participants, Group 2 fixed its first attention on the face of both the influencer and the curvy Primark model (Table 8) earlier than Group 1 in all cases, with the 
only significant difference being for the influencer, both in a bikini (TFF $=0.95 ; p=0.007$ ) and in street clothes (TFF $=1.08 ; p=0.018$ ). In the case of imperfections, the skin fold was seen earlier by Group 2 in a non-significant way, both for the bikini influencer (TFF $=3.16 ; p=0.158$ ) and the curvy bikini model $(\mathrm{TFF}=3.14 ; p=0.198)$. However, Group 1 paid significant attention to the skin fold of the influencer in street clothes $(\mathrm{TFF}=2.03 ; p=0.038)$. Attention to the abdomen was fixed earlier in Group 1, both in a bikini (TFF $=1.14 ; p=0.271)$ and in street clothes (TFF $=1.33 ; p=0.101)$. However, attention to the curvy Primark model in street clothes was focused earlier for Group 2 (TFF $=0.35 ; p=0.808$ ), but not in a bikini (TFF $=2.86 ; p=0.276$ ). In none of these cases were the differences significant. There were also no significant differences between the two groups in fixing their attention for the first time on the bust in a bikini or in street clothes.

The total average duration of fixation on each AOI (Table 9) was significantly longer in Group 2 in the case of the influencer (TFD $=1.01 ; p=0.023$ ) and the curvy model (TFD $=0.66 ; p=0.804$ ), both in a bikini, whereas with street clothes, the influencer also received more attention in Group 2 (TFD $=1.23 ; p=0.302)$, as did the Primark model in Group 1 (TFD $=1.00 ; p=0.001)$. Greater attention was paid to the skin fold of the influencer in street clothes in the publication in which she mentioned it expressly, with a greater incidence in Group 1 (TFD $=0.91 ; p=0.343$ ), although Group 2 paid significantly prolonged attention to the skin fold of the bikini influencer (TFD $=0.57 ; p=0.019$ ). Although no significant differences were observed between the groups, the abdomen notably attracted greater attention for the influencer in a bikini with respect to street clothes, with the opposite being true for the curvy Primark model. The only significant difference between the groups regarding the time they spent in relation to clothes was with the bag worn by the Primark model in street clothes, with a longer duration in the case of Group 2 (TFD $=0.95 ; p=0.024)$.

The average number of eye fixations (Table 10) was much higher in the case of the influencer, especially when dressed in street clothes, although the only significant difference between both groups occurred on the face of the curvy model in street clothes, with more fixations by Group 1 (TFD = 2.40; $p=0.001$ ).

Regarding the average duration of each of these eye fixations (Table 11), Group 2 had a longer average duration on the face, skin fold, and belly of the influencer in the two stimuli, whereas Group 1 had the same with the curvy Primark models, with the differences being non-significant, except in the case of the curvy brand model wearing street clothes ( $\mathrm{FD}=0.28 ; p=0.050)$. The average duration of attention to the bust of the influencer in a bikini and to the shirt was equal in both AOIs and both groups $(\mathrm{FD}=0.24)$. The average duration of attention was scarcely higher without a significant difference in Group 1 with respect to the curvy Primark models. However, the accessories (belt, bag, and shoes) registered longer durations in Group 2, with significant differences in the case of the bag ( $F D=0.45$; $p=0.048)$. 
Table 8. Kruskal-Wallis test. Time from fixation (TFF) means by stimulus, group, and AOI.

\begin{tabular}{|c|c|c|c|c|c|c|c|c|c|c|c|c|c|c|c|}
\hline \multirow{3}{*}{ AOI } & \multicolumn{3}{|c|}{ E1 } & \multicolumn{4}{|c|}{ E2 } & \multicolumn{4}{|c|}{ E3 } & \multicolumn{4}{|c|}{ E4 } \\
\hline & \multicolumn{2}{|c|}{ Average TFF } & \multirow{2}{*}{$p$-Value } & \multirow{2}{*}{ AOI } & \multicolumn{2}{|c|}{ Average TFF } & \multirow{2}{*}{$p$-Value } & \multirow{2}{*}{ AOI } & \multicolumn{2}{|c|}{ Average TFF } & \multirow{2}{*}{$p$-Value } & \multirow{2}{*}{ AOI } & \multicolumn{2}{|c|}{ Average TFF } & \multirow{2}{*}{$p$-Value } \\
\hline & G1 & G2 & & & G1 & G2 & & & G1 & G2 & & & G1 & G2 & \\
\hline AOI 1 & 1.17 & 0.95 & 0.007 * & AOI 1 & 1.41 & 1.08 & 0.018 * & AOI 1 & 0.89 & 0.73 & 0.358 & AOI 1 & 0.66 & 0.57 & 0.434 \\
\hline AOI 2 & 3.18 & 2.49 & 0.158 & AOI 2 & 0.39 & 0.52 & 0.138 & AOI 2 & 1.75 & 1.70 & 0.295 & AOI 2 & 1.29 & 1.00 & 0.140 \\
\hline AOI 3 & 3.24 & 3.16 & 0.636 & AOI 3 & 2.03 & 2.67 & 0.038 * & AOI 3 & 3.73 & 3.56 & 0.850 & AOI 3 & 1.52 & 1.98 & 0.187 \\
\hline AOI 4 & 2.66 & 2.41 & 0.338 & AOI 4 & 1.33 & 2.05 & 0.101 & AOI 4 & 1.12 & 1.32 & 0.645 & AOI 4 & 1.89 & 2.07 & 0.082 \\
\hline AOI 5 & 1.41 & 1.16 & 0.126 & & & & & AOI 5 & 1.62 & 1.52 & 0.706 & AOI 5 & 1.41 & 1.35 & 0.808 \\
\hline AOI 6 & 1.77 & 1.73 & 0.774 & & & & & AOI 6 & 2.66 & 2.86 & 0.276 & AOI 6 & 2.74 & 2.95 & 0.223 \\
\hline \multirow[t]{4}{*}{ AOI 7} & 1.14 & 1.51 & 0.271 & & & & & AOI 7 & 1.77 & 2.48 & $0.007^{*}$ & & & & \\
\hline & & & & & & & & AOI 8 & 2.93 & 2.47 & 0.226 & & & & \\
\hline & & & & & & & & AOI 9 & 2.78 & 3.07 & 0.144 & & & & \\
\hline & & & & & & & & AOI 10 & 3.47 & 3.14 & 0.198 & & & & \\
\hline
\end{tabular}

Note: * denotes significant differences.

Table 9. Kruskal-Wallis test. Total fixation duration (TFD) means by stimulus, group, and AOI.

\begin{tabular}{|c|c|c|c|c|c|c|c|c|c|c|c|c|c|c|c|}
\hline \multicolumn{4}{|c|}{ E1 } & \multicolumn{4}{|c|}{ E2 } & \multicolumn{4}{|c|}{ E3 } & \multicolumn{4}{|c|}{ E4 } \\
\hline \multirow{2}{*}{ AOI } & \multicolumn{2}{|c|}{ Average TFD } & \multirow{2}{*}{$p$-Value } & \multirow{2}{*}{ AOI } & \multicolumn{2}{|c|}{ Average TFD } & \multirow{2}{*}{$p$-Value } & \multirow{2}{*}{ AOI } & \multicolumn{2}{|c|}{ Average TFD } & \multirow{2}{*}{$p$-Value } & \multirow{2}{*}{ AOI } & \multicolumn{2}{|c|}{ Average TFD } & \multirow{2}{*}{$p$-Value } \\
\hline & G1 & G2 & & & G1 & G2 & & & G1 & G2 & & & G1 & G2 & \\
\hline AOI 1 & 0.86 & 1.01 & $0.023 *$ & AOI 1 & 1.14 & 1.23 & 0.302 & AOI 1 & 0.65 & 0.66 & 0.804 & AOI 1 & 1.00 & 0.68 & $0.001 *$ \\
\hline AOI 2 & 0.35 & 0.46 & 0.334 & AOI 2 & 1.83 & 1.96 & 0.345 & AOI 2 & 0.58 & 0.59 & 0.414 & AOI 2 & 0.53 & 0.53 & 0.912 \\
\hline AOI 3 & 0.43 & 0.57 & 0.019 * & AOI 3 & 0.91 & 0.78 & 0.343 & AOI 3 & 0.42 & 0.40 & 0.850 & AOI 3 & 0.43 & 0.42 & 0.629 \\
\hline AOI 4 & 0.43 & 0.36 & 0.786 & AOI 4 & 0.38 & 0.41 & 0.845 & AOI 4 & 0.64 & 0.64 & 0.664 & AOI 4 & 0.76 & 0.95 & 0.024 * \\
\hline AOI 5 & 0.84 & 0.84 & 0.505 & & & & & AOI 5 & 0.81 & 0.72 & 0.244 & AOI 5 & 0.78 & 0.64 & 0.150 \\
\hline AOI 6 & 0.50 & 0.52 & 0.854 & & & & & AOI 6 & 0.41 & 0.37 & 0.302 & AOI 6 & 0.92 & 1.11 & 0.251 \\
\hline \multirow[t]{4}{*}{ AOI 7} & 1.84 & 1.74 & 0.618 & & & & & AOI 7 & 0.39 & 0.35 & 0.371 & & & & \\
\hline & & & & & & & & AOI 8 & 0.39 & 0.44 & 0.125 & & & & \\
\hline & & & & & & & & AOI 9 & 0.40 & 0.41 & 0.589 & & & & \\
\hline & & & & & & & & AOI 10 & 0.45 & 0.40 & 0.679 & & & & \\
\hline
\end{tabular}


Table 10. Kruskal-Wallis test. Fixations count (FC) means by stimulus, group, and AOI.

\begin{tabular}{|c|c|c|c|c|c|c|c|c|c|c|c|c|c|c|c|}
\hline \multirow{3}{*}{ AOI } & \multicolumn{3}{|c|}{ E1 } & \multicolumn{4}{|c|}{ E2 } & \multicolumn{4}{|c|}{ E3 } & \multicolumn{4}{|c|}{ E4 } \\
\hline & \multicolumn{2}{|c|}{ Average FC } & \multirow{2}{*}{$p$-Value } & \multirow{2}{*}{ AOI } & \multicolumn{2}{|c|}{ Average FC } & \multirow{2}{*}{$p$-Value } & \multirow{2}{*}{ AOI } & \multicolumn{2}{|c|}{ Average FC } & \multirow{2}{*}{$p$-Value } & \multirow{2}{*}{ AOI } & \multicolumn{2}{|c|}{ Average FC } & \multirow{2}{*}{$p$-Value } \\
\hline & G1 & G2 & & & G1 & G2 & & & G1 & G2 & & & G1 & G2 & \\
\hline AOI 1 & 2.95 & 3.18 & 0.449 & AOI 1 & 3.97 & 4.02 & 0.703 & AOI 1 & 2.02 & 2.32 & 0.105 & AOI 1 & 2.40 & 1.74 & 0.001 * \\
\hline AOI 2 & 1.14 & 1.25 & 0.666 & AOI 2 & 7.65 & 8.20 & 0.163 & AOI 2 & 1.57 & 1.56 & 0.754 & AOI 2 & 2.16 & 2.18 & 0.614 \\
\hline AOI 3 & 1.38 & 1.59 & 0.133 & AOI 3 & 2.57 & 2.03 & 0.088 & AOI 3 & 1.60 & 1.29 & 0.231 & AOI 3 & 1.46 & 1.34 & 0.157 \\
\hline AOI 4 & 1.47 & 1.33 & 0.484 & AOI 4 & 1.74 & 1.63 & 0.532 & AOI 4 & 2.63 & 2.69 & 0.627 & AOI 4 & 2.12 & 2.31 & 0.304 \\
\hline AOI 5 & 3.58 & 3.54 & 0.585 & & & & & AOI 5 & 2.56 & 2.67 & 0.378 & AOI 5 & 2.67 & 2.54 & 0.598 \\
\hline AOI 6 & 2.31 & 2.20 & 0.458 & & & & & AOI 6 & 1.44 & 1.43 & 0.789 & AOI 6 & .214 & 2.36 & 0.661 \\
\hline \multirow[t]{4}{*}{ AOI 7} & 7.32 & 6.73 & 0.250 & & & & & AOI 7 & 1.54 & 1.57 & 0.753 & & & & \\
\hline & & & & & & & & AOI 8 & 1.36 & 1.43 & 0.871 & & & & \\
\hline & & & & & & & & AOI 9 & 1.40 & 1.37 & 0.522 & & & & \\
\hline & & & & & & & & AOI 10 & 1.41 & 1.32 & 0.455 & & & & \\
\hline
\end{tabular}

Note: * denotes significant differences.

Table 11. Kruskal-Wallis test. Fixation duration (FD) means by stimulus, group, and AOI.

\begin{tabular}{|c|c|c|c|c|c|c|c|c|c|c|c|c|c|c|c|}
\hline \multirow{3}{*}{ AOI } & \multicolumn{3}{|c|}{ E1 } & \multicolumn{4}{|c|}{ E2 } & \multicolumn{4}{|c|}{ E3 } & \multicolumn{4}{|c|}{ E4 } \\
\hline & \multicolumn{2}{|c|}{ Average FD } & \multirow{2}{*}{$p$-Value } & \multirow{2}{*}{ AOI } & \multicolumn{2}{|c|}{ Average FD } & \multirow{2}{*}{$p$-Value } & \multirow{2}{*}{ AOI } & \multicolumn{2}{|c|}{ Average FD } & \multirow{2}{*}{$p$-Value } & \multirow{2}{*}{ AOI } & \multicolumn{2}{|c|}{ Average FD } & \multirow{2}{*}{$p$-Value } \\
\hline & G1 & G2 & & & G1 & G2 & & & G1 & G2 & & & G1 & G2 & \\
\hline AOI 1 & 0.33 & 0.35 & 0.130 & AOI 1 & 0.30 & 0.33 & 0.172 & AOI 1 & 0.35 & 0.31 & 0.293 & AOI 1 & 0.45 & 0.42 & 0.710 \\
\hline AOI 2 & 0.31 & 0.36 & 0.341 & AOI 2 & 0.24 & 0.24 & 0.430 & AOI 2 & 0.40 & 0.42 & 0.426 & AOI 2 & 0.26 & 0.24 & 0.677 \\
\hline AOI 3 & 0.31 & 0.38 & 0.203 & AOI 3 & 0.37 & 0.39 & 0.486 & AOI 3 & 0.26 & 0.31 & 0.427 & AOI 3 & 0.31 & 0.32 & 0.716 \\
\hline AOI 4 & 0.27 & 0.28 & 0.800 & AOI 4 & 0.21 & 0.25 & 0.302 & AOI 4 & 0.26 & 0.25 & 0.383 & AOI 4 & 0.38 & 0.45 & $0.048^{*}$ \\
\hline AOI 5 & 0.24 & 0.24 & 0.919 & & & & & AOI 5 & 0.36 & 0.28 & $0.008^{*}$ & AOI 5 & 0.28 & 0.25 & 0.050 * \\
\hline AOI 6 & 0.22 & 0.23 & 0.373 & & & & & AOI 6 & 0.29 & 0.26 & 0.074 & AOI 6 & 0.44 & 0.50 & 0.238 \\
\hline \multirow[t]{4}{*}{ AOI 7} & 0.25 & 0.25 & 0.471 & & & & & AOI 7 & 0.26 & 0.23 & 0.129 & & & & \\
\hline & & & & & & & & AOI 8 & 0.28 & 0.29 & 0.053 & & & & \\
\hline & & & & & & & & AOI 9 & 0.28 & 0.31 & 0.287 & & & & \\
\hline & & & & & & & & AOI 10 & 0.35 & 0.32 & 0.475 & & & & \\
\hline
\end{tabular}

Note: ${ }^{*}$ denotes significant differences. 


\section{Discussion}

Communication in organizations revolves around their stakeholders, and social networks have allowed their value to be created through mutual interaction and integrated communication, shaping a permeable system that can be decentralized within the organization [45]. The growth experienced by Instagram and its wide influence as a social network that has common interests with the female population under 25 who are interested in topics such as beauty and fashion, has promoted its integration into the communication strategies of brands, which have found a method of conveying greater credibility and proximity in their messages by using the power of influencers.

These influencers are primarily young women, as were the participants in this research, as observed in their everyday personal life narratives, which improves the credibility to the message they deliver [23]. This is why promotion by influencers with many followers, who have reached a celebrity status, decreases the perceived uniqueness of a brand [24]. Conversely, influential citizens offer trust, sympathy, similarity, and familiarity by exerting that influence on their followers in terms of fashion issues through Instagram [46].

In qualitative research, participants acknowledge that by publishing self-photographs on Instagram they are concerned about how others perceive their appearance, and they compare their image with those of others and the likes they received [47]. Along these lines, neuroscience has shown that young people prefer photographs published by others on Instagram that have a higher number of likes [21], with the added danger that teenagers more positively value manipulated self-photos than the originals [48], with no differences in body dissatisfaction when being exposed before models, peers, or classmates [19]. Narcissism has been reported as one of the reasons for showing intense activity on Instagram, whereas its use is perceived as "cool". Its use is aimed at seeking social approval and allows for a comparison with other people with a high level of social activity [49].

However, some vulnerabilities with social media usage are related to the creation of personal identity and self-esteem, which are put at risk by the activity generated on Instagram by its users. Although, specifically regarding the visualization of images in cases that have been treated as eating disorders, some authors stated that body dissatisfaction is predictive of this type of disorder [50], in which the female community is usually the only one studied. The few authors who compared male and female stimuli with eye tracking found no significant differences in attention [51]. In this regard, the curvy girl movement has promoted increased acceptance of large women in relation to the image that beauty and fashion brands have traditionally communicated, which is consistent with the idea that the mere repeated exposure of a person to a stimulus improves one's attitude toward it [52].

Some fashion brands have joined this action by including models of various sizes as well as by using curvy influencers in their communication campaigns. Studies with eye tracking have shown that visual attention to a product focused on the elements of the brand is related to greater efficiency in advertising [41] and that fashion brands are recognized mainly through accessories [53]. Other research has confirmed that the appearance of large models in advertisements improves the attractiveness of the brand to women of all sizes, as opposed to men [54], and that the display of idealized images on social networks negatively influences women's body image [55].

Although the scientific literature indicates greater recall of and persuasive power exerted by influencers who recommend fashion when compared to communications by the fashion brands themselves, due to the former's credibility, spontaneity, and interaction, the results indicate that when a curvy influencer appears in a bikini, attention is first focused on the imperfections about which she is raising awareness before the fashion she is promoting, contrary to what occurs when the model appears in another type of clothing.

The results are consistent with other eye tracking studies, which have revealed the tendency to look at unattractive areas rather than areas that are attractive, comparing one's own body to that of others [56-59], which is associated with a lower satisfaction with one's own body [60]. The areas with the highest number of glances and the longest glance duration were the following: the abdominal region (for the majority of all the groups), groin and lower ribs [61], chest [62], buttocks, upper legs, 
and, in general, the parts of the body without clothes [63], because patients with eating disorders, on which these references are focused, spend more time looking at parts of the body with which they are most dissatisfied [64]. In other words, the influence of cognitive biases on levels of dissatisfaction is evident in all body image research [65].

The attention paid to models of the low-cost fashion brand Primark was distributed more evenly throughout all the elements of image, as much on the clothes as on the accessories and imperfections, whether they were promoting street clothes or bikinis. Both the influencer and the fashion brand model received attention fixations on the main garments, t-shirt, and dress, which were close to $100 \%$ of the participants, reflecting the potential of both.

Regarding attention paid to the influencer or to the brand model, the persuasive impact of the fondness for the influencer who is habitually followed is notable, since her face captures more lasting and intense attention from the participants, despite the face of the brand model receiving the initial attention. Regarding attention to imperfections, there were no significant differences between the influencer and the brand model; as such, both can raise awareness successfully, without ignoring the importance of the more positive attitude that followers have toward influencers than to fashion advertising. These imperfections receive more and faster attention in the images where they are more visible. The participants focused more attention on influencers and curvy models than on thin models, even sharing the same image, although the points of interest were similar in both cases, which could diminish the negative effects of repeated exposure to ideal photographs [21,56], which endorses the greater attractiveness of large-size models in advertisements for all groups of women [54]. When both were wearing street clothes, Primark's model captured more attention that lasted longer and was more intense compared with the main fashion garment heavily promoted by the influencer.

The comparison of a curvy model to a thin model, both in bikinis, allowed us to verify that the face, bust, and abdomen of the curvy model received considerably more attention than those of the thin model, with no significant differences detected in the attention paid to the lower abdominal area. Various researchers [66-68] have observed that young women feel worse after being exposed to women who are toned, though not only because they are thin, as was the case in previous decades. In addition, these researchers have stated that the curvy ideal is not harmed by being displayed next to the slim ideal, as this research confirms. The slim model received less attention by appearing next to the curvy model, though this does not necessarily imply an improvement in the perception of one's own body image, since women who have internalized the slim ideal are more vulnerable in their body appraisal [69]. In this sense, mediation in the area of body acceptance, such as that conducted by the curvy influencers on Instagram, increases young girls' resilience toward the thin ideal [70].

Although there were no major differences between the two groups, the one from Spain showed significantly faster attention (TFF) with longer duration (TFD) toward the face of the influencer, both in clothing and in a bikini, which seems to be a logical consequence, since most of the Spanish participants already know the influencer, whereas the Portuguese participants demonstrated a significantly higher number of fixations (FC) and a longer total duration (TFD) on the face of the Primark model in street clothes. Regarding imperfections, the Spanish group also provided faster attention (TFF), and longer duration (TFD) to the skin folds for which the influencer in a bikini aimed to raise awareness, whereas the Portuguese group differed significantly by registering a longer average duration of each attention fixation (FD) to the abdomen of the curvy Primark model in a bikini and that of the brand model dressed in street clothes. In relation to clothing, the Portuguese group paid significantly greater attention (TFD) to the bag of the Primark model in street clothes, although the Spanish group registered a longer average duration in each fixation (FD).

\section{Conclusions}

We conclude (Figure 3) that even though the influencer received more attention than the curvy Primark models, both received more attention than the thin brand model, which reflects the affinity of the audience. This attention was focused more on the imperfections about which awareness 
was being raised, rather than on the clothes they were promoting, contrary to what occurred in the brand communications.

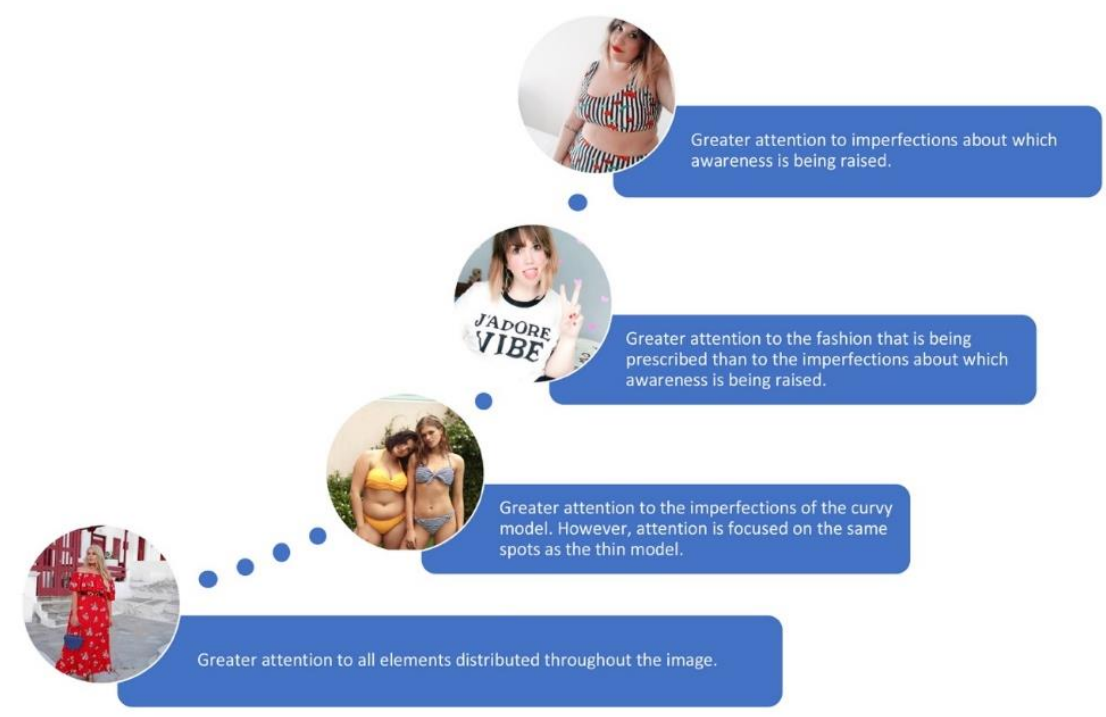

Figure 3. Main conclusions for each stimulus.

\subsection{Recommendations}

The results show that brands should reconsider some of their strategies in relation to the decision to use curvy influencers, depending on whether their communication objectives consider social responsibility in the creation of identity in social networks, or only the promotion of their product or fashion brand, both of which are compatible issues, as demonstrated by some low-cost brands like Primark. Thus, the main recommendation for management is to consider a diversity of model sizes in brand communication campaigns. From the area of cognitive processing, this research has contributed to the consolidation of the change in the literature on positive body image that has evolved [71].

\subsection{Study Limitations}

The main limitation of the research was in the sample size (60 participants per group). However, the sample size was higher than that of other studies based on eye tracking (between 15 and 50 participants). There was also a cultural bias in having conducted the study in two culturally similar countries, which is necessary in a context of a globalized brand strategy [72]. Although the use of social networks may be similar across cultures, the reasons why they are used are not. Thus, less individualistic countries, such as those in Europe, on which this research was based, use Instagram more oriented toward social interaction than self-promotion, as is the case in the United States [72]. Finally, the selection of participants was consistent with the main user profile of Instagram, and although the research was conducted in two specific universities, these institutions were characterized by a diversity of students from all over the country.

\subsection{Future Research Opportunities}

Future research should expand the results obtained in this research by recording the emotions that these stimuli arouse in participants, for which it will be necessary to incorporate the galvanic skin response (GSR). In addition, the results should be contrasted with those that can provide participants with geographical, cultural, gender, or age diversity.

Author Contributions: Conceptualization, L.M.-V., A.-I.V., and U.C.-C.; methodology, A.-I.V., and U.C.-C.; software, L.M.-V., and A.-I.V.; validation, U.C.-C., and A.-I.V.; investigation, L.M.-V., A.-I.V., and U.C.-C.; writing-original draft preparation, L.M.-V., and A.-I.V.; writing-review and editing, U.C.-C., and A.-I.V. 
Funding: This research received no external funding.

Conflicts of Interest: The authors declare no conflict of interest.

\section{References}

1. IABspain.es. Annual Report of Social Media 2017. Available online: https://bit.ly/2oLsUaU (accessed on 6 June 2019).

2. Marktest.com. The Portuguese and Social Media 2017. Available online: https://bit.ly/2K1CmTq (accessed on 6 June 2019).

3. ComScore.com. 2017 U.S. Mobile App Report. Available online: https://bit.ly/2zZaGbn (accessed on 6 June 2019).

4. The-cocktail.com. Observatory on Social Media. VIII Stage. Available online: https://bit.ly/2K12ugS (accessed on 6 June 2019).

5. Instagram.com. Instagram.com. 700 Millions. Available online: https://bit.ly/2q5lBcv (accessed on 6 June 2019).

6. Brandwatch.com. Instagram Statistics for 2016. Available online: https://bit.ly/2ddlBTX (accessed on 6 June 2019).

7. Targhi, A.T. Similarity measurement for describe user images in social media. Int. J. Nonlinear Anal. Appl. 2017, 8, 291-299. [CrossRef]

8. Shumaker, C.; Loranger, D.; Dorie, A. Dressing for the Internet: A study of female self-presentation via dress on Instagram. Fash. Style Pop. Cult. 2017, 4, 365-382. [CrossRef]

9. Reece, A.; Danforth, C.M. Instagram photos reveal predictive markers of depression. EPJ Data Sci. 2017, 6, 15. [CrossRef]

10. Hendrickse, J.; Arpan, L.M.; Clayton, R.B.; Ridgway, J.L. Instagram and college women's body image: Investigating the roles of appearance-related comparisons and intrasexual competition. Comput. Hum. Behav. 2017, 74, 92-100. [CrossRef]

11. Etgar, S.; Amichai-Hamburguer, Y. Not All Selfies Took Alike: Distinct Selfie Motivations Are Related to Different Personality Characteristics. Front. Psychol. 2017, 8, 842. [CrossRef] [PubMed]

12. Webb, J.B.; Vinoski, E.R.; Bonar, A.S.; Davies, A.E.; Etzel, L. Fat is fashionable and fit: A comparative content analysis of Fatspiration and Health at Every Size (R) Instagram images. Body Image 2017, 22, 53-64. [CrossRef]

13. Clayton, R.B.; Ridgway, J.L.; Hendrickse, J. Is plus size equal? The positive impact of average and plus-sized media fashion models on women's cognitive resource allocation, social comparisons, and body satisfaction. Commun. Monogr. 2017, 84, 406-422. [CrossRef]

14. Slater, A.; Varsani, N.; Diedrichs, P.C. \#fitspo or \#loveyourself? The impact of fitspiration and self-compassion Instagram images on women's body image, self-compassion, and mood. Body Image 2017, 22, 87-96. [CrossRef]

15. Ahadzadeh, A.S.; Sharif, S.P.; Ong, F.S. Self-schema and self-discrepancy mediate the influence of Instagram usage on body image satisfaction among youth. Comput. Hum. Behav. 2017, 68, 8-16. [CrossRef]

16. Primack, B.A.; Shensa, A.; Sidani, J.E.; Whaite, E.O.; Lin, L.Y.; Rosen, D.; Colditz, J.B.; Radovic, A.; Miller, E. Social Media Use and Perceived Social Isolation Among Young Adults in the U.S. Am. J. Prev. Med. 2017, 53, 1-8. [CrossRef]

17. Pittman, M.; Reich, B. Social media and loneliness: Why an Instagram picture may be worth more than a thousand Twitter words. Comput. Hum. Behav. 2016, 62, 155-167. [CrossRef]

18. Turner, P.G.; Lefevre, C.E. Instagram use is linked to increased symptoms of orthorexia nervosa. Eat Weight Disord.-Stud. Anorex. Bulim. Obes. 2017, 22, 277-284. [CrossRef] [PubMed]

19. Brown, Z.; Tiggermann, M. Attractive celebrity and peer images on Instagram: Effect on women's mood and body image. Body Image 2016, 19, 37-43. [CrossRef] [PubMed]

20. Djafarova, E.; Rushworth, C. Exploring the credibility of online celebrities' Instagram profiles in influencing the purchase decisions of young female users. Comput. Hum. Behav. 2017, 68, 1-7. [CrossRef]

21. Sherman, L.E.; Greenfield, P.M.; Hernández, L.M.; Dapretto, M. Peer Influence Via Instagram: Effects on Brain and Behavior in Adolescence and Young Adulthood. Child Dev. 2017, 89, 37-47. [CrossRef] [PubMed] 
22. Casalo, L.V.; Flavian, C.; Ibáñez-Sánchez, S. Understanding Consumer Interaction on Instagram: The Role of Satisfaction, Hedonism, and Content Characteristics. Cyberpsychol. Behav. Soc. Netw. 2017, 20, 369-375. [CrossRef] [PubMed]

23. Abidin, C. Visibility labour: Engaging with Influencers' fashion brands and \#OOTD advertorial campaigns on Instagram. Media Int. Aust. 2016, 161, 86-100. [CrossRef]

24. De-Veirman, M.; Cauberghe, V.; Hudders, L. Marketing through Instagram influencers: The impact of number of followers and product divergence on brand attitude. Int. J. Advert. 2017, 36, 798-828. [CrossRef]

25. Lu, D.Y.; Sang, J.T.; Chen, Z.N.; Xu, M.; Mei, T. Who Are Your "Real” Friends: Analyzing and Distinguishing Between Offline and Online Friendships from Social Multimedia Data. IEEE Trans. Multimed. 2017, 19, 1299-1313. [CrossRef]

26. Lup, K.; Trub, L.; Rosenthal, L. Instagram \#Instasad? Exploring Associations Among Instagram Use, Depressive Symptoms, Negative Social Comparison, and Strangers Followed. Cyberpsychol. Behav. Soc. Netw. 2015, 18, 247-252. [CrossRef]

27. Marcus, S.R. Thinspiration vs. thicksperation: Comparing pro-anorexic and fat acceptance image posts on a photo-sharing site. Cyberpsychol.-J. Psychosoc. Res. Cyberspace 2017, 10. [CrossRef]

28. Roelens, I.; Baecke, R.; Benoit, D.F. Identifying influencers in a social network: The value of real referral data. Decis. Support Syst. 2016, 91, 25-36. [CrossRef]

29. Griggs, L.; Freilich, A. Influencers, Instagurus, and Enablers: Using Accessorial Liability to Establish a Norm of Behaviour in Relation to Disguised Viral Marketing. Aust. J. Compet. Consum. Law 2017, 25, 113-123.

30. Rosental, S.; McKeown, K. Detecting Influencers in Multiple Online Genres. ACM Trans. Internet Technol. 2017, 17. [CrossRef]

31. Ribeiro-Cardoso, P.; Teixeira, S.; Santos, A.L. Fashion opinion leadership, innovativeness and attitude toward advertising among Portuguese consumers. Mediterr. J. Commun. 2016, 7, 101-115. [CrossRef]

32. Madan, C.R. Neuromarketing: The Next Step in Market Research? Eureka 2010, 1, 34-42. [CrossRef]

33. Ariely, D.; Berns, G.S. Neuromarketing: The Hope and Hype of Neuroimaging. Bus. Nat. Rev. Neurosci. 2010, 11, 284-292. [CrossRef]

34. Duchowski, A. Eye Tracking Methodology: Theory and Practice; Springer: London, UK, 2013; ISBN 978-1-84628-608-7.

35. Intraub, H. The role of implicit naming in pictorial encoding. J. Exp. Psychol. 1979, 5, 78-87. [CrossRef]

36. Bornstein, R.F.; D'Agostino, P.R. Stimulus recognition and the mere exposure effect. J. Personal. Soc. Psychol. 1992, 63, 545-552. [CrossRef]

37. Pieters, R.; Warlop, L.; Wedel, M. Breaking through the clutter: Benefits of advertisement originality and familiarity for brand attention and memory. Manag. Sci. 2002, 48, 765-781. [CrossRef]

38. Goodrich, K. Anarchy of effects? Exploring attention to online advertising and multiple outcomes. Psychol. Mark. 2011, 28, 417-440. [CrossRef]

39. Loftus, G.R.; Kallman, J.J. Encoding and use of detail information in picture recognition. J. Exp. Psychol. 1979, 5, 197-211. [CrossRef]

40. Cuesta-Cambra, U.; Niño-González, J.I.; Rodríguez-Terceño, J. The Cognitive processing of an educational app with EEG and eye tracking. Comunicar 2017, 52, 41-50. [CrossRef]

41. Zhang, X.; Yuan, S.M.; Chen, M.D.; Liu, X. A Complete System for Analysis of Video Lecture Based on Eye Tracking. Access IEEE 2018, 6, 49056-49066. [CrossRef]

42. Cuesta-Cambra, U.; Martínez-Martínez, L.; Niño-González, J.I. An analysis of pro-vac-cine and anti-vaccine information on social networks and the internet: Visual and emotional patterns. El Prof. Inf. 2019, 28, e280217. [CrossRef]

43. Kerr-Gaffney, J.; Harrison, A.; Tcanturia, K. Eye-tracking research in eating disorders: A systematic review. Int. J. Eat. Disord. 2018, 52, 3-27. [CrossRef] [PubMed]

44. Alaños, E. EyeTracker Technology in elderly people: How integrated television content is paid attention to and processed. Comunicar 2015, 23, 75-83. [CrossRef]

45. Reto, F.; Rauschnabel, P.A.; Hinsch, C. Elements of strategic social media marketing: A holistic framework. J. Bus. Res. 2017, 70, 118-126. [CrossRef]

46. Martensen, A.; Brockenhuus-Schack, S.; Zahid, A.L. How citizen influencers persuade their followers. J. Fash. Mark. Manag. 2018, 22, 335-353. [CrossRef] 
47. Baker, N.; Ferszt, G.; Breines, J.G. A Qualitative Study Exploring Female College Students' Instagram Use and Body Image. Cyberpsychol. Behav. Soc. Netw. 2019, 22, 277-282. [CrossRef]

48. Kleemans, M.; Daalmans, S.; Caarbat, I.; Anschutz, D. Picture Perfect: The Direct Effect of Manipulated Instagram Photos on Body Image in Adolescent Girls. Media Psychol. 2018, 21, 93-110. [CrossRef]

49. Sheldon, P.; Bryant, K. Instagram: Motives for its use and relationship to narcissism and contextual age. Comput. Hum. Behav. 2016, 58, 89-97. [CrossRef]

50. White, C.; Newman, L.S.; Voss, D. A confound-free test of the effects of thin-ideal media images on body satisfaction. J. Soc. Clin. Pshychol. 2016, 35, 822-839. [CrossRef]

51. Phillipou, A.; Rossell, S.L.; Gurvich, C.; Castle, D.J.; Troje, N.F.; Abel, L.A. Body image in anorexia nervosa: Body size estimation utilising a biological motion task and eyetracking. Eur. Eat. Disord. Rev. 2016, 24, 131-138. [CrossRef] [PubMed]

52. Zajonc, R.B. Attitudinal effects of mere exposure. J. Personal. Soc. Psychol. 1968, 9, 1-27. [CrossRef]

53. Amatulli, C.; Guido, G.; Mileti, A.; Tomacelli, C.; Prete, M.I.; Longo, A.E. Mix-and-Match' Fashion Trend and Luxury Brand Recognition: An Empirical Test Using Eye-tracking. Fash. Theory 2016, 20, 341-362. [CrossRef]

54. Aagerup, U.; Scharf, U.R. Obese models' effect on fashion brand attractiveness. J. Fash. Mark. Manag. 2018, 22, 557-570. [CrossRef]

55. Fardouly, J.; Holland, E. Social media is not real life: The effect of attaching disclaimer-type labels to idealized social media images on women's body image and mood. New Media Soc. 2018, 20, 4311-4328. [CrossRef]

56. Bauer, A.; Schneider, S.; Waldorf, M.; Braks, K.; Huber, T.J.; Adolph, D.; Vocks, S. Selective Visual Attention Towards Oneself and Associated State Body Satisfaction: An Eye-Tracking Study in Adolescents with Different Types of Eating Disorders. J. Abnorm. Child Psychol. 2017, 45, 1647-1661. [CrossRef]

57. Svaldi, J.; Caffier, D.; Tuschen-Caffier, B. Attention to ugly body parts is increased in women with binge eating disorder. Psychother. Psychosom. 2011, 80, 186-188. [CrossRef]

58. Svaldi, J.; Bender, J.; Caffier, D.; Ivanova, V.; Mies, N.; Fleischhaker, C.; Tuschen-Caffier, B. Negative mood increases selective attention to negatively valenced body parts in female adolescents with anorexia nervosa. PLoS ONE 2016, 11, e0154462. [CrossRef] [PubMed]

59. Tuschen-Caffier, B.; Bender, C.; Caffier, D.; Klenner, K.; Braks, K.; Svaldi, J. Selective visual attention during mirror exposure in anorexia and bulimia nervosa. PLoS ONE 2015, 10, e0145886. [CrossRef] [PubMed]

60. Blechert, J.; Ansorge, U.; Tuschen-Caffier, B. A body-related dotprobe task reveals distinct attentional patterns for bulimia nervosa and anorexia nervosa. J. Abnorm. Child Psychol. 2010, 119, 575-585. [CrossRef] [PubMed]

61. Cornelissen, K.K.; Cornelissen, P.L.; Hancock, P.J.B.; Tovée, M.J. Fixation patterns, not clinical diagnosis, predict body size over-estimation in eating disordered women and healthy controls. Int. J. Eat. Disord. 2016, 49,507-518. [CrossRef] [PubMed]

62. Von Wietersheim, J.; Kunzl, F.; Hoffmann, H.; Glaub, J.; Rottler, E.; Traue, H. Selective attention of patients with anorexia nervosa while looking at pictures of their own body and the bodies of others: An exploratory study. Pscychosom. Med. 2012, 74, 107-113. [CrossRef] [PubMed]

63. Horndasch, S.; Kratz, O.; Holczinger, A.; Heinrich, H.; Hönig, F.; Nörth, E.; Moll, G.H. Looks do matter-Visual attentional biases in adolescent girls with eating disorders viewing body images. Psychol. Res. 2012, 198, 321-323. [CrossRef] [PubMed]

64. Freeman, R.; Touyz, S.; Sara, G.; Rennie, C.; Gordon, E.; Beumont, P. In the eye of the beholder: Processing body shape information in anorexic and bulimic patients. Int. J. Eat. Disord. 1991, 10, 709-714. [CrossRef]

65. Rodgers, R.F.; DuBois, R.H. Cognitive biases to appearance-related stimuli in body dissatisfaction: A systematic review. Clin. Psychol. Rev. 2016, 46,1-11. [CrossRef]

66. Mulgrew, K.E.; Hennes, S.M. The effect of functionality- and aesthetic-focused images on Australian women's body satisfaction. Sex Roles 2015, 72, 127-139. [CrossRef]

67. Tiggemann, M.; Zaccardo, M. 'Strong is the new skinny': A content analysis of \#fitspiration images on Instagram. J. Health Psychol. 2016, 23, 1003-1011. [CrossRef]

68. Betz, D.E.; Ramsey, L.R. Should women be "All About That Bass?": Diverse body-ideal messages and women's body image. Body Image 2017, 22, 18-31. [CrossRef] [PubMed]

69. Halliwell, E. The impact of thin idealized media images on body satisfaction: Does body appreciation protect women from negative effects? Body Image 2013, 10, 509-514. [CrossRef] [PubMed]

70. Halliwell, E.; Dietrichs, P.C. Brief Report: Testing a dissonance body image intervention among young girls. Health Psychol. 2013, 33, 201-204. [CrossRef] [PubMed] 
71. Halliwell, E. Future directions for positive body image research. Body Image 2015, 14, 177-189. [CrossRef] [PubMed]

72. Sheldon, P.; Rauschnabel, P.A.; Antony, M.G.; Car, S. A cross-cultural comparison of Croatian and American social network sites: Exploring cultural differences in motives for Instagram use. Comp. Hum. Behav. 2017, 75, 643-651. [CrossRef] 